\title{
The role of customer management capabilities in public-private partnerships
}

Ana Isabel Canhoto

Department of Marketing, Faculty of Business, Oxford Brookes University, Oxford, England

adomingos-canhoto@brookes.ac.uk

Maureen Meadows

Department for Strategy and Marketing, The Open University Business School, Open

University, Milton Keynes, England

maureen.meadows@open.ac.uk

Kirstie Ball

Department for People and Organisations, The Open University Business School, Open University, Milton Keynes, England

kirstie.ball@open.ac.uk

Elizabeth Daniel

Department for Strategy and Marketing, The Open University Business School, Open University, Milton Keynes, England

elizabeth.daniel@open.ac.uk

Sally Dibb

Department for Strategy and Marketing, The Open University Business School, Open University, Milton Keynes, England

sally.dibb@open.ac.uk

Keith Spiller

Department of Criminology, School of Social Sciences, Birmingham City University,

Birmingham, England

keith.spiller@bcu.ac.uk

\section{Acknowledgments}

The authors would like to thank the Leverhulme Trust for funding the study reported in this paper. They would also like to thank the managers and staff in the organizations that participated in this study for sharing their expertise.

\begin{abstract}
Commercial organisations are increasingly asked to perform tasks traditionally associated with governmental bodies, such as law enforcement. The rationale for these public-private partnerships is that there are synergies between traditional business skills and those required to achieve certain societal goals. However, there is a lack of research into whether this is, indeed, the case. This paper addresses this gap by investigating one particular type of public-private partnership: anti-money laundering (AML). The study explores the potential synergies between customer relationship management (CRM) and those required for AML. A quantitative survey-based approach is used to identify the overlaps and connections between these two areas of competence. The findings reveal tensions between financial institutions' dual roles as both commercial
\end{abstract}


organisations and players in the battle against money laundering. The consequences for these firms are explored, and the wider implications for other organisations supplying non-commercial services to government are considered.

Keywords: Marketing Capabilities; Public-private partnerships; Customer Relationship Management; Anti Money Laundering; Customer Insight 


\section{Introduction}

Organisations increasingly deliver solutions by forming partnerships that bring together different parties with relevant capabilities (Gebauer, Paiola, \& Saccani, 2013). This trend reflects a drive towards rationalisation, with each organisation focusing on what they do best (Holcomb \& Hitt, 2007). Such partnerships are particularly prevalent in the public sector (Percival, 2009; Porter \& Kramer, 2011), where governments have engaged commercial organisations to deliver services that they would not otherwise be able to provide. The potential efficiency benefits and cost savings have made this approach popular with governments of all political denominations (Brown \& Potoski, 2004), in areas as diverse as education (Resh \& Pitts, 2013), food safety (Hutter \& Jones, 2007), national security (Dibb et al., 2014), waste management (Brown \& Potoski, 2004) or welfare (Meyers, Riccucci, \& Lurie, 2001). Despite the widespread belief that commercial organisations are best placed to carry out such functions, there is a lack of research on how firms use their commercial capabilities to address societal problems (Lindgreen, Hingley, Grant, \& Morgan, 2012). This is a significant problem in the light of the recent proliferation of public-private partnerships because the ability to perform well requires the deployment of the right capabilities (e.g., Krasnikov \& Jayachandran, 2008; Theodosiou, Kehagias, \& Katsikea, 2012).

This research investigates the extent to which traditional marketing capabilities enable commercial organisations to meet the requirements of public-private partnerships. We focus on the financial services sector, where public-private partnerships have proliferated to support the detection of money laundering and the prevention of terrorism financing - henceforth referred to as AML programs (deGoede, 2012). The continued unrest in the Middle East, South East Asia and North Africa, as well as the increasing tensions in Eastern Europe, have led governments worldwide to widen their efforts to curtail the movement of money to and from criminal organisations (e.g., BBC, 2014; USDS, 2014), with the result that the involvement of private firms in the public sphere is likely to expand. A priority, therefore, is to examine the extent to which the capabilities of commercial organisations enable them to support law enforcement initiatives and, where conflict exists, how it is addressed. We tackle this problem through the following two-part research question: To what extent do marketing capabilities in CRM enable financial services firms to support law enforcement initiatives; and how are conflicts that arise negotiated? The paper's contribution is twofold: firstly, we reveal areas of alignment and non-alignment between the capabilities required for CRM systems and AML programmes and consider the implications for the sector. Secondly, we contribute to the wider debate about the theory and practice surrounding the implementation of public-private partnerships.

The next section briefly describes the research context and the following one presents the conceptual framework, identifying the marketing capabilities that are likely to support the law enforcement initiative and developing a series of propositions which underpin the study. The subsequent section outlines the methods used, and this is followed by a section presenting the findings, which highlights overlaps and connections between the marketing capabilities and the law enforcement requirements. The final section discusses the sector-specific implications and explores the broader implications of the study. 


\section{Research background}

Crime is deemed to cause social, environmental and economic harm (FATF, 2010), leading governments worldwide to adopt initiatives to curtail criminal activity. One example are AML programmes, which focus on limiting the movement of money resulting from, or used to fund, criminal activity. If governments hinder the transfer of funds to or from criminals, a reduction in the underlying criminal activity is expected (Harvey, 2005). As a result, the tracing and mining of financial data has assumed a critical role in modern national security programs worldwide (DeRosa, 2004).

Given the role of financial institutions as global enablers of financial transactions (Zdanowicz, 2004), governments worldwide are expecting these organisations to play an active role in AML programmes. In the UK, AML regulations relate to the Proceeds of Crime Act (2002), which applies to organisations operating in a range of sectors, including banks, building societies and insurance businesses. Here, the financial regulator puts forward two instruments for financial institutions to use in order to aid in AML: 'know your customer' and 'monitoring'. Know your customer is described as 'obtaining and using information about a customer over and above the basic identification information', whereas monitoring is 'being alert to how a customer is using a firm's products and services and therefore to signs of money laundering' (FSA, 2003). That is, for financial institutions to be able to meet AML requirements, they need to have the right customer identification and transaction monitoring capabilities in place. They also need to employ a Money Laundering Reporting Officer (MLRO) who has legal responsibility for ensuring compliance with the regulations (Levi \& Gilmore, 2002). In cases where financial organisations believe that suspicious transactions have taken place, they are legally obligated to report these to the National Crime Agency (Backhouse, Canhoto, Demetis, Dyer, \& Nardo, 2005).

In principle, financial institutions should be able to meet both of these requirements by drawing on existing capabilities to capture and manage customer identity and transaction data. These firms use customer relationship management (CRM) systems to marshal this data in order to minimize exposure to bad debt and to be responsive to customer needs (Capon, 1982; Ryals \& Payne, 2001). CRM systems bring together customer related information from multiple sources in the organisation (Sheth, Sisodia, \& Sharma, 2000) as well as from outside of the firm (Richard, Thirkell, \& Huff, 2007), yielding insights about customers (Johnson, Clark, \& Barczak, 2012), their lifetime value (Lindgreen, Palmer, Vanhamme, \& Wouters, 2006), market trends (Stein, Smith, \& Lancioni, 2013), and supporting the development of differentiated marketing approaches (Zablah, Bellenger, \& Johnston, 2004). We propose that there is an overlap between these CRM capabilities and those required to assist the government in AML programs.

\section{Conceptual framework}

The conceptual framework we use to investigate the alignment between CRM and AML capabilities is developed from literature on the conditions that support CRM competence, as summarised in Figure 1. The framework, which is developed from Dibb and Meadows (2004) and supported by other CRM implementation studies (e.g., Henneberg, 2006), classifies the capabilities that support CRM into hard and soft factors. The hard factors concern the use of technology and the effective capture and 
use of customer data, while the soft factors relate to the company itself and the role of staff. In line with previous studies on CRM, the framework further assumes the need for certain pre-requisites, specifically in relation to the strategic commitment towards the ideas that underlie CRM.

[Insert Figure 1 here]

\section{Pre-requisites of CRM competence}

Previous studies suggest that different organisations, even from the same sector, have reached different stages of evolution in their CRM journey (Karakostas, Kardaras, \& Papathanassiou, 2005). These variations reflect the differing strategic orientation and priorities of these firms (Bohling et al., 2006) which, in turn, shape the capabilities that are developed (Morgan, Vorhies, \& Mason, 2009). In the case of CRM, capabilities are shaped by the senior management's belief in the role of relationships with key customers in the creation of shareholder value (Payne \& Frow, 2005). Another influencing factor is the organisation's culture, namely whether there is a clearly articulated vision regarding the importance of identifying customer needs and whether performance systems explicitly consider CRM activities (Meadows \& Dibb, 2012). Given that AML also relies on efficient capture and response of customer and transaction data, we propose the following:

\section{Proposition 1: Competence in AML is positively associated with a number of} established pre-requisites for competence in CRM.

\section{Hard factors supporting CRM competence}

While CRM processes may function with little investment in technology (Keramati, Mehrabi, \& Mojir, 2010), today's data driven environment means that many firms deploy information technology systems to support their CRM initiatives (Johnson et al., 2012). A consequence is that CRM systems have become the backbone of managing customer relationships (Chuang \& Lin, 2013) with their significance depending on the quality of customer information available. Bhatt, Emdad, Roberts, and Grover (2010) argue that to obtain full value from these systems and remain responsive to environmental changes, the technological infrastructure needs to have highly flexible data access and sharing. In view of the data requirements for AML, we expect similar competences to CRM will be needed. We therefore propose that:

\section{Proposition 2: Competence in AML is positively associated with a number of established dimensions of CRM implementation concerning the strategic deployment of technology.}

Johnson et al. (2012) argue that the main function of CRM technology is to support customer management capabilities. A tenet of relationship marketing is that the development of relationships between firms and customers is based on commitment and trust (Morgan \& Hunt, 1994). Hence, an additional hard factor to consider is the capability to understand customers and their needs, calculate acquisition and retention 
costs, and establish a program of regular contact with consumers. Since AML also requires access to high quality customer data, we propose that:

\section{Proposition 3: Competence in AML is positively associated with a number of established dimensions of CRM implementation concerning customer data/knowledge capabilities.}

\section{Soft factors supporting CRM competence}

Companies may implement initiatives that support a one-to-one future, such as the adoption of distribution channels or the development of products that support a close relationship with customers. It has been shown (e.g., Grewal, Comer, \& Mehta, 2001) that evidence shows that the success of marketing initiatives is determined by the motivation of the firm to embrace change and the resources it dedicates to implement these initiatives. Programs to support the development of relationships with customers are no exception, requiring a concerted effort from the whole organisation in order to succeed (Vandermerwe, 2004). A key company capability is therefore the ability to integrate and share information beyond functional units (De Luca \& Atuahene-Gima, 2007). We expect that this same capability will be central to the firm's ability to comply with AML requirements and propose that:

Proposition 4. Competence in AML is positively associated with a number of established dimensions of CRM implementation concerning the organisation's strategic focus on customer centricity.

The second type of soft factor considers the role that employees play in retaining customers, how they communicate with customers and whether they are empowered to make decisions that support the relationship. Success in the CRM journey is largely influenced by the extent to which the organisation has in-depth understanding of the broad range of people, processes, operations and technology issues associated with CRM implementation (Bohling et al., 2006). Finnegan and Currie (2010) argue that CRM success is hindered by an excessive focus on specific software packages. Instead, software deployment should be secondary to defining and developing appropriate customer-facing business processes, including the recruitment and training of customer-focused staff (Johnson et al., 2012). Employees' affective commitment, for instance, is a key factor in the successful implement of CRM initiatives (Shum, Bove, $\&$ Auh, 2008). In addition, employees need to possess the necessary technical skills to be able to use the system to its full potential (Keramati et al., 2010). Those who have access to customer insight and are part of cross-functional teams are deemed to be more responsive to customer needs and better able to assess relationship development opportunities (Sethi, 2000; Troy, Hirunyawipada, \& Paswan, 2008). Since we expect competence in AML also requires similar cross-functional support, we propose that:

Proposition 5. Competence in AML is positively associated with a number of established dimensions of CRM implementation concerning the management and behaviours of staff that support relationship-based interactions with customers. 


\section{Methodology}

To explore the propositions, we adopted a positivist approach based on quantitative data gathering via a survey. The data were gathered through self-administered questionnaires distributed via a web link to a convenience sample of managers working in the financial services sector. Adopting a quantitative approach enabled us to explore correlations between factors.

Data gathering in the financial services sector is notoriously difficult, a situation compounded by the banking crisis of 2009 and subsequent economic recession. Furthermore, the subject matter of this research is deemed by many firms to be highly sensitive: financial institutions are very reluctant to discuss their approach to money laundering and terrorism financing detection for legal, strategic and operational reasons (Backhouse et al., 2005). In order to promote completion of the survey, we enlisted the support of several different industry bodies who helped to share the survey link. Overall, 281 responses were received, of which 85 were fully completed. We found that respondents who did not have direct involvement in AML tended to choose not to complete the AML section of the survey, hence the relatively low proportion of respondents who completed every question on the survey. Our analysis exploring AML and its linkages with CRM was therefore confined to the 85 responses that were fully completed.

The CRM parts of the survey were based on previously validated scales (Dibb \& Meadows, 2004; Meadows \& Dibb, 2012) which identify and elaborate upon the dimensions of CRM sophistication. These were complemented with new questions about the extent and impact of AML initiatives. These questions were drawn up by the research team based on a review of relevant literature and complemented by insights from key informant interviews with financial services experts. Key issues that emerged included how customer data is collected and analysed, as well as the roles, responsibilities and training of staff, and the management of AML projects more broadly. Table 1 provides an overview of the survey instrument and the topics covered. Appendix A gives further details of the question asked. Respondents evaluated items on a scale from 1 to 7 , with opposing views at either end of the scale. Analysis consisted of descriptive statistics, correlations and exploratory factor analysis. The analysis followed the accepted view (e.g., Hair, Black, Babin, \& Andersen, 2009; Robinson, Shaver, \& Wrightsman, 1991) that the lower limit of Cronbach's alpha for exploratory studies such as this one may decrease to 0.6 from the usual 0.7 .

[Insert Table 1 here]

\section{Findings}

Around half of the respondents were from large organisations, with turnover exceeding $£ 500 \mathrm{~m}$ and/or more than 3000 employees. The respondents represented a range of firms, from building societies (6\%) to insurance companies (21\%), and including high street $(17 \%)$, investment (14\%) and online banks (16\%), among others $(26 \%)$.

\section{$A M L$ requirements and CRM competence}


In order to consider the extent to which marketing capabilities in CRM help to support AML enforcement, we fist consider the responses to questions about the impact of AML requirements and examine the degree of CRM maturity in relation to the four dimensions of CRM implementation. Appendix A provides descriptive statistics for each question. To achieve high levels of scale reliability, the original 7 questions in Proposition 1 were reduced to 4, yielding a Cronbach's alpha value of 0.884 . Similarly, the 9 questions originally in Proposition 2 were reduced to 5, yielding a Cronbach's alpha value of 0.632; the 6 questions in Proposition 3 were reduced to 3, yielding a Cronbach's alpha value of 0.651 ; the 9 questions in Proposition 4 were reduced to 4 , yielding a Cronbach's alpha value of 0.774; and the 6 questions in Proposition 5 were reduced to 2, yielding a Cronbach's alpha value of 0.636 . In addition, the questions concerning the AML requirements were reduced from 15 to 12, as explained in relation to Table 2, which follows later.

Part 1 of the descriptive statistics in Appendix A, which concerns the AML requirements, show that respondents tend to agree strongly with the statements that front-line staff have clear responsibility for reporting on unusual data that they observe, and that staff training has changed as a result of AML. In addition, these projects seem to be strongly supported and permeate all parts of the organisation. The findings also suggest that the ways in which data are captured and analysed have changed as a result of AML, indicating that firms have needed to adapt existing practices in these areas.

Parts 2 to 6 of the descriptive statistics in Appendix A, Pre-Requisites for CRM, and the four dimensions of CRM implementation, reveal a range of CRM sophistication levels among the firms responding. Just over $40 \%$ of respondents reported that their organisation had a CRM team. In terms of the pre-requisites for CRM, most respondents reported a strong stated desire for relationship management within their firms, and an organisational culture that had a flexible approach to innovation and change. Many respondents felt that CRM had a strong champion in their own organisation, and that CRM projects were proactively supported by senior management - but such views were not universally expressed.

Turning to the two 'hard' dimensions of CRM implementation - the use of technology, and the need to build and use customer data effectively - our study shows that the staff in many of the responding organisations still feel constrained by the limited range of customer data that they have available to them (for instance when handling customer enquiries). Some front-line staff still do not have access to data on customer attitudes, behaviours and life events, for example, and there may appear to be a lack of coordination in some organisations between staff in front line roles and those who are more removed from the customer-facing side of the business, for instance organising direct marketing activities. This may explain why respondents from some firms report that when dealing with customers, there focus is mainly transactional, rather than - for example - updating the customer data that is available on the system.

The survey also explored the two 'softer' dimensions of CRM implementation, around the company itself and the role of staff. Here, it appears that there is less strong support for the notion that CRM projects permeate all parts of the organisations, in comparison with AML activity; support is typically felt to be less strong than for AML projects. Respondents report a tendency in some firms to focus on customer groups rather than individual customers, and on transactions rather than on customer life events, even during day-to-day contacts with customers that present market research 
opportunities. The overall picture is one of a wide spectrum of progress with CRM, with some firms reaching much higher levels of sophistication than others.

We now explore each of the main research propositions ( 1 to 5 ) in turn, in order to understand how AML competence is influenced by each of the established key dimensions of CRM competence.

\section{The relationship between AML competence and pre-requisites for successful CRM (P1)}

Statistically significant correlations were found between four items representing known pre-requisites for CRM (Pre1 to Pre4 in Appendix A) and eight items representing key AML issues (labelled Req1 to Req12). Strong correlations between CRM prerequisites on the one hand, and changing job roles due to AML on the other, apply to both front line staff and those handling customer data. We find that changes in the ways in which the data are analysed due to AML (Req2) are associated with the idea that the organisational culture is well suited to supporting CRM (Pre4; $r=0.251$, $\mathrm{p}=0.044)$. Changing responsibilities for staff, and in particular the view that front-line staff have clear responsibility for reporting on unusual data that they observe (Req12), is associated with the notion that senior management are proactive in supporting CRM projects (Pre3; $r=0.239, p=0.005$ ). Changes in staff training as a result of AML (Req5) are associated with a number of pre-requisites for CRM, including a proactive senior management team that champions CRM (Pre3; $\mathrm{r}=0.342, \mathrm{p}=0.004$ ) and articulates a desire for relationship management in the organisation (Pre1; $\mathrm{r}=0.369, \mathrm{p}=0.002$ ). Changes in systems, such as agreement with the proposition that the organisation has designed systems with AML in mind ((Req11) are associated with a number of CRM pre-requisites, particularly a proactive senior management team (Pre3; $r=0.263$, $\mathrm{p}=.034$ ) and a supportive culture (Pre $4 ; \mathrm{r}=0.249, \mathrm{p}=0.045)$. There is a strong association between management support for CRM projects and management support for AML projects. If the goal is for AML to permeate all parts of the organisation (Req10), both the support that management show for CRM (Pre3; $r=0.320, p=0.009$ ) and a culture that is well suited to CRM (Pre4; $r=0.331, p=0.006$ ) can help to achieve this outcome. The proposition that AML projects are supported very strongly (Req9) is correlated with a proactive role of senior management in supporting CRM projects (Pre3; $r=0.293$, $\mathrm{p}=0.018)$.

Overall, this analysis provides evidence for a relationship between established pre-requisites for successful CRM (such as a stated desire for relationship marketing, a proactive senior management team who champion CRM and a culture that supports CRM) and AML competence (as suggested by changes to job roles, data analysis, systems and staff training, for example).

\section{The relationship between AML competence and dimensions of CRM implementation concerning the strategic deployment of technology (P2)}

Statistically significant correlations were found between four items representing the role of technology in the implementation of CRM (labelled T1 to T5) and five items representing key AML issues. Our analysis provides evidence of a relationship between established dimensions of CRM around technology deployment (such as access by staff in different roles to a range of customer data, and co-ordination between staff in different roles) and AML competence (as suggested by changes to data capture, 
data analysis and systems, for example). We found strong correlations between the access of staff to customer data when handling enquiries and the ways in which AML has changed both data capture and data analysis. The propositions of change in both data capture (Req1; $\mathrm{r}=0.294, \mathrm{p}=0.017$ ) and data analysis (Req2; 0.291, $\mathrm{p}=0.019$ ) are strongly correlated with the statement that front line staff have access to a range of customer data (rather than only basic customer data) when handling customer enquiries (T2). This suggests that two key areas of progress with AML - changes in data capture and data analysis - are supported by improved access to customer data as required by CRM projects.

Changes in data capture and analysis are likely to be reflected in changes to relevant systems. The idea that the organisation has designed systems with AML in mind (Req11) is associated with two items around more sophisticated data access and data use. This indicates that progress with CRM, such as the recognition of data as a strategic tool $(\mathrm{T} 1 ; \mathrm{r}=0.297, \mathrm{p}=0.0170)$ and associated improvements in the customer data available to staff (T4; $\mathrm{r}=0.333, \mathrm{p}=0.007$ ), may support the provision of systems that are mindful of the needs of AML activity. The idea that AML permeates all parts of the organisation (Req10) is associated with two questions around data access (T2; $\mathrm{r}=0.38, \mathrm{p}=0.002$; and information sharing ( $\mathrm{T} 5 ; \mathrm{r}=0.253, \mathrm{p}=0.04$ ). Finally, the idea that AML projects are supported very strongly (Req9) is associated with the issue that front line staff have access to a range of customer data when handling customer enquiries (T2; $\mathrm{r}=0.290, \mathrm{p}=0.019$ ). Again, we see that successful AML may be supported by competence in CRM such as good practice in data access and data sharing.

\section{The relationship between AML competence and dimensions of CRM implementation concerning customer knowledge capabilities (P3)}

Statistically significant correlations were found between two items representing customer-facing issues in the implementation of CRM (labelled Cust2 and Cust3) and five items representing key AML issues. The notion that the organisation has designed systems with AML in mind (Req11) is associated with the company's competence at anticipating and reacting to customer needs (events based marketing, Cust $3 ; r=0.286$, $\mathrm{p}=0.022$ ). There are also statistically significant correlations between the statement that during customer contact, the organisation tends to emphasise updating customer information systems rather than simply recording transactions (Cust2), and four items representing key aspects of AML, namely the idea that AML has changed the job role for those handling customer data (Req8; $\mathrm{r}=.319, \mathrm{p}=0.011)$; the notion that the ways in which data are captured have changed as a result of AML (Req1; $r=0.327, p=0.009$ ); the idea that staff training has changed as a result of AML (Req5; $r=0.252, p=0.042$ ); and the statement that the organisation's approach to dealing with customers has changed as a result of AML (Req3; $r=0.277, p=0.029$ ).

Our data therefore suggests a relationship between established dimensions of CRM around customer knowledge (such as desire to keep customer data up-to-date, and to anticipate and respond to customer needs) and AML competence (as suggested by changes to job roles, data capture, systems and staff training, for example).

The relationship between AML competence and dimensions of CRM implementation concerning the organisation's strategic focus on customers (P4) 
Statistically significant correlations (as reported in Appendix B) were found between three items representing key company issues in the implementation of CRM (labelled $\mathrm{Co} 1$ to $\mathrm{Co} 3$ ) and three items representing key AML issues. Our study provides evidence for a relationship between established dimensions of CRM around the company's strategy (such as a focus on building relationships with individual customers) and AML competence (as suggested by changes to job roles and approaches to dealing with customers, for example).

The dimensions of CRM implementation relating to the organisation itself provide significant support for AML competence. For instance, the idea that AML has changed the job role of front line staff (Req7) is associated with the question around the emphasis on customer-driven/life event-led marketing rather than transactiondriven marketing $(\mathrm{Co} 1 ; \mathrm{r}=0.284, \mathrm{p}=0.024)$. The notion that the organisation's approach to dealing with customers has changed as a result of AML (Req3) is associated with a particular question around the company always focusing on the individual rather than customer groups $(\mathrm{Co} 2 ; \mathrm{r}=0.261, \mathrm{p}=0.036$. Moreover, the idea that AML permeates all parts of the organisation (Req10) is associated with the question around the company focusing on relationship building rather than increasing sales volumes as the route to competitive advantage ( $\mathrm{Co} 3 ; \mathrm{r}=0.33, \mathrm{p}=0.007)$.

\section{The relationship between AML competence and dimensions of CRM implementation concerning the management/ behaviours of staff (P5)}

Statistically significant correlations were found between two items representing key staff issues in the implementation of CRM (labelled S1 and S2) and three items representing key AML issues. Our data shows that two key aspects of change relating to AML are supported by a single item around the nature of objective-setting for staff. The notion that staff training has changed as a result of AML (Req5) and the notion that the frequency of customer contact has changed as a result of AML (Req4) are both associated with the question around senior management setting objectives which reflect the company stance on CRM ( $\mathrm{S} 1$, for Req5; $\mathrm{r}=0.267, \mathrm{p}=0.027$; and for Req4; $\mathrm{r}=0.262$, $\mathrm{p}=0.035)$. The idea that the data accessible to front line staff have changed as a result of AML (Req6) is associated with two questions (S1 and S2) around objective setting ( $\mathrm{S} 1 ; \mathrm{r}=0.404, \mathrm{p}=0.001$ and more sophisticated data gathering $(\mathrm{S} 2 ; \mathrm{r}=0.298, \mathrm{p}=0.018$ ). We therefore find evidence for a relationship between established dimensions of CRM around staff (such as the setting of appropriate objectives) and AML competence (as suggested by changes to customer data, customer contact and staff training, for example).

\section{Exploring AML and CRM competence via Factor Analysis}

To further examine the respondents' views, an exploratory factor analysis (EFA) was conducted. The analysis examined the underlying constructs represented by the measurement items. A factor analysis with Varimax rotation was used to assess the 15 measurement items developed for AML requirements (see Table 2). Following prior studies (e.g., Lai, Wong, \& Cheng, 2010), items with a factor loading of 0.5 or above were retained, and items with a factor loading below 0.5 were eliminated to purify the model (Hair et al., 2009). 12 items remained in four factors, accounting for $75.1 \%$ of the total variance. Construct dimensionality was examined by performing Bartlett's test of sphericity and the Kaiser-Meyer-Olkin (KMO) measure of sampling adequacy. The 
former was $392.3(\mathrm{p}=0.000)$ and the latter 0.768 . The values suggest that the intercorrelation matrix contains enough common variance to make factor analysis worth pursuing (Norusis, 2002).

[Insert Table 2 here]

The four resulting factors are labelled as follows: Gathering and Analysing Customer Data, Changing Job Roles for Staff, Organisational Support for AML and Systems and Responsibilities. All Cronbach's alpha reliability values for the factors exceeded the required thresholds of 0.6 . While most sections of the questionnaire drew on previously validated scales, the AML scale was new; hence the importance of identifying reliable constructs with acceptable alpha values.

The first factor focuses on changes in the nature of customer data gathering and analysis, what and how the data are captured. It also refers to changes in the organisation's approach to dealing with customers including the frequency of customer contact; this is backed up by changes in staff training. The second factor concerns changes in the job roles of front line staff and those handling customer data, and draws upon related changes for front line staff, such as the customer data that are accessible to them. The third factor concerns wider organisational issues such as the support for AML projects, and whether AML permeates the whole organisation. The fourth factor is about the clear responsibility that front line staff have to report on unusual data, and the design of systems with AML in mind. Overall, while the four factors are drawn from the AML questions, they suggest a strong connection with the four dimensions of CRM implementation covered elsewhere in the survey. Thus the first factor is concerned mainly with issues of the Customer (and customer data/knowledge), the second with Staff, the third with the Company itself and the fourth with Technology. This finding once again suggests the strength of the inter-connections between practices in CRM and AML. It also provides support for the propositions that were set out earlier, in that organisational strengths in these areas are related to competence in both CRM and AML. These ideas are explored further via the qualitative data presented next.

\section{Discussion and Conclusion}

Financial services organisations have a noted history of gathering and utilising customer data, leading to a reputation for pioneering the field of customer relationship management. Our study shows clear overlaps between the firms' CRM capabilities, and their potential to implement AML successfully. This finding aligns with previous studies suggesting that marketing capabilities are an important route to deploying and implementing strategic orientations (such as a strong market and customer focus) that are linked to superior firm performance (Theodosiou et al., 2012). However, we also find tensions between the capabilities needed for effective CRM systems and those needed to implement AML programmes. There are consequences for how financial services organisations gear up to deal with AML requirements, as well as insights in relation to the wider debate concerning the implementation of public-private partnerships. Dealing first with the issues for the financial services sector, we begin by summarising the key findings from the study: 
- There are strong links between certain CRM pre-requisites and perceived competence in AML. For example, visible support for CRM, demonstrated for instance via a strong championing of CRM projects and an articulated strategic appetite for successful CRM, is associated with changing job roles around AML; with new modes of data analysis and staff responsibilities around CRM (such as reporting on unusual data); and is related to changes in the organisation's systems to reflect the demands of AML. Support for CRM is associated with support for AML, and with the recognised need for both initiatives to permeate all parts of the company.

- There are interconnections between areas of CRM competence related to technology, such as improved access to customer data related to CRM initiatives, and a range of areas of progress with AML, such as data capture, data analysis, support for AML projects and the notion that AML concepts are permeating throughout the firm. Systems changes to support AML may also be connected to key CRM ideas such as progress with the concept of the strategic role of data in the firm, and improved data access.

- Strong associations are evident between positive steps associated with customer knowledge in CRM projects on the one hand, such as the desire and ability to get to know the customer better and to anticipate customer needs; and competence in AML on the other hand, such as making appropriate changes to systems, to data capture and analysis, and to staff roles and training.

- Competence in key areas of AML, such as making effective changes to job roles and to customer handling, are supported by dimensions of CRM progress concerning the organisation's strategic focus, such as a paradigm shift from transactional marketing to customer relationship-based marketing which recognises the need to focus on the individual customer and to build relationships over time.

- The importance of staff behaviours and management in relation to AML competence is emphasised by the study. AML competence is supported by positive CRM experience, such as objective setting to promote progress with CRM, using regular customer contact opportunities to get to know the customer better, making better data available to staff, changing the frequency of customer contact and changing staff training to support AML.

However, even though we found synergies between the tasks required for CRM and AML, we also found that AML requires engagement in specific activities which go beyond those required by CRM. Given that AML and CRM systems are designed to profile for different purposes; one for risk, and the other for attractiveness or potential profitability of the customer, this is not particularly surprising. These differences in required outcomes from CRM and AML raise clear conflicts between the firms' commercial roles and their regulatory responsibilities in relation to money laundering. We suspect these conflicts are likely to be sharply felt by staff in front line roles, who are required to maintain their normal high standard of customer service at the same time as acting upon 'suspicious' data that has come to their attention. In these cases, the desire to provide seamless customer service and delight customers in order to generate referrals may be hindered by the requirement to be suspicious of the customers' activities, report customers or even avoid explaining the full situation if the customer is under investigation. 
Turning to the additional changes required to organisational activities that are over and above those already undertaken as part of CRM, we find that AML requires the collection of specific data, enhanced skills in specific forms of data analysis, a range of 'soft' skills on the part of the organisation's staff, and a particular commitment to AML that will ideally permeate the whole organisation. The customer profiling based on data generated for AML purposes (and not for CRM purposes) may be based on tacit knowledge about the customers, and such data are not generally shared across the organisation. We also find that the requirements for AML impact organisations differently, for instance as a result of the size of the organisation and we suspect that smaller organisations can find compliance particularly costly. Nevertheless, our analysis suggests that firms are seeking to engage positively with AML, and to maximise its potential benefits for the industry (including increasing safety and legitimacy).

We further find that many survey respondents appear to have accepted, if not fully embraced, AML requirements. They see the value of increased legitimacy and safety, a position no doubt influenced by the increased visibility of business practices due to the evolution of technology, particularly social media, which gives citizens access to information, as well as a voice (Kotler, 2012). However, we also found that the impact of AML on the financial institutions goes well beyond the data collected and its treatment. The discourse around AML and, in particular, the role of banks emphasises the ubiquitous collection of data and electronic recording of transactions.

We now focus on the broader contributions to the debate about the implementation of public-private partnerships. As previously noted, commercial organisations are increasingly involved in performing tasks that would traditionally be associated with the public sector; they are often seeking solutions to complex problems by forming partnerships that bring together different parties with relevant capabilities (Gebauer et al., 2013). Although we have explored the synergies and tensions that can arise in one such public-private partnership, we expect the findings to have implications for other types of public-private partnerships. These implications fall into three areas which we discuss in turn: first, the deployment of relevant capabilities and the impact of strategic orientation on the outcomes of these partnerships; second, the tensions that arise between the firms' commercial objectives and their regulatory responsibilities; and third, the operational complexities that are associated with implementation.

The ability to achieve a strong organisational performance depends upon the deployment of relevant capabilities and the deployment of valuable marketing capabilities can act as an important mediator in the implementation of an organisation's strategic orientation (Theodosiou et al., 2012). In our study, we found that the deployment of marketing capabilities that are used to support customer management, also helped to underpin compliance with AML. In line with previous findings, we also found that the strategic orientation of the firms helped to shape these capabilities (Morgan et al, 2009). We expect that deploying existing commercial capabilities will underpin and support the implementation of activities required in other public-private partnership. A word of caution concerns the varying levels of sophistication that we found in relation to CRM and AML and the dangers in assuming that the capabilities are sufficient to ensure that all firms can readily comply. Such a differential could have consequences for the success of other types of public-private partnership, particular if negative impacts on the competitiveness of organisations and levels of customer service impact upon commercial outcomes. For example, in the travel market, the requirements placed on airlines and other carriers by e-Borders placed smaller operators at a 
considerable disadvantage (Ball et al., 2015). These concerns reflect our second point, which relates to the pressures that are brought to bear on available resources and the tensions that are created between the commercial objectives of firms and the need to comply with regulatory requirements.

Finally, we consider the additional operational complexities and their implication for public private partnerships. The literature on integrated solutions, such as the private-public partnership discussed in this paper, argues that while firms may face increased operational complexity (Nordin, Kindström, Kowalkowski, \& Rehme, 2011) they should be able to benefit from access to new resources and customer insight for use in their business development (Jaakkolaa \& Hakanen, 2013). Although this may not automatically be the case, as shown by this particular private-public partnership, it does raise important questions for both researchers and practitioners. Commercial organisations are now regularly called upon to support the government in solving societal problems. It is therefore important to research the impact on the organisations involved of their inability to generate commercial benefits from such partnerships. Ultimately, an inability to generate commercial benefits is also likely to impact upon the success of these private-public schemes, and this should be explored further. In other sectors, firms have been shown to manage the negative consequences of compliance and restore their commercial interests by engaging in a process described as "recognizing, rationalizing and refashioning" (Dibb et al., 2014). Future research should explore the prevalence of such approaches in other industry sectors where public and private organisations are working together, and explore the further implications for practice in the sectors affected.

\section{References}

Backhouse, J., Canhoto, A. I., Demetis, D., Dyer, B., \& Nardo, M. (2005). Spotlight: New approaches to fighting Money Laundering (pp. 134). London: London School of Economics.

Ball, K., Canhoto, A. I., Daniel, E., Dibb, S., Meadows, M., \& Spiller, K. (2015). The Private Security State? Surveillance, Consumer Data and the War on Terror. Copenhagen: Copenhagen Business School Press.

BBC. (2014, 10 December 2104). New Zealand approves new anti-terror laws. BBC News Asia.

Bhatt, G., Emdad, A., Roberts, N., \& Grover, V. (2010). Building and leveraging information in dynamic environments: The role of IT infrastructure flexibility as enabler of organizational responsiveness and competitive advantage. Information \& Management, 47(4-8), 341-349.

Bohling, T., Bowman, D., LaValle, S., Mittal, V., Narayandas, D., Ramani, G., \& Varadarajan, R. (2006). CRM Implementation: Effectiveness Issues and Insights. Journal of Service Research, 9(2), 184-194.

Brown, T. L., \& Potoski, M. (2004). Managing the Public Service Market. Public Administration Review, 64(6), 656-668.

Capon, N. (1982). Credit-scoring systems: a critical analysis. Journal of Marketing, 46(2), 82-91.

Chuang, S.-H., \& Lin, H.-N. (2013). The roles of infrastructure capability and customer orientation in enhancing customer-information quality in CRM systems: Empirical evidence from Taiwan. International Journal of Information Management, 33(2), 271-281. 
De Luca, L. M., \& Atuahene-Gima, K. (2007). Market knowledge dimensions and cross-functional collaboration: Examining the different routes to product innovation performance. Journal of Marketing, 71(1), 95-112.

deGoede, M. (2012). Speculative Security - The politics of pursuing terrorist monies. Minneapolis, MN: University of Minnesota Press.

DeRosa, M. (2004). Data Mining and Data Analysis for Counterterrorism (Vol. 68). Washington DC: Center for Strategic and International Studies.

Dibb, S., Ball, K., Canhoto, A. I., Daniel, E., Meadows, M., \& Spiller, K. (2014). Taking responsibility for border security: Commercial interests in the face of e-borders. Tourism management, 42(June), 50-61.

Dibb, S., \& Meadows, M. (2004). Relationship Marketing and CRM: a financial services case study. Journal of Strategic Marketing, 12, 111-125.

FATF. (2010). Global Money Laundering \& Terrorist Financing Threat Assessment - A view of how and why criminals and terrorists abuse finances, the effect of this abuse and the steps to mitigate these threats (pp. 75). Paris: Financial Action Task Force.

Finnegan, D. J., \& Currie, W. L. (2010). A multi-layered approach to CRM implementation: An integration perspective. European Management Journal, 28(2), 153-167.

FSA. (2003). Reducing money laundering risk - Know your customer and antimoney laundering monitoring (pp. 48). London: Financial Services Authority.

Gebauer, H., Paiola, M., \& Saccani, N. (2013). Characterizing service networks for moving from products to solutions. Industrial Marketing Management, 42(1), 31-46.

Grewal, R., Comer, J. M., \& Mehta, R. (2001). An Investigation into the Antecedents of Organizational Participation in Business-to-Business Electronic Markets. Journal of Marketing, 65(3), 17-33.

Hair, J. F., Black, W. C., Babin, B. J., \& Andersen, R. E. (2009). Multivariate Data Analysis (7th ed.). New Jersey: Prentice Hall.

Harvey, J. (2005). An Evaluation of Money Laundering Policies. Journal of Money Laundering Control, 8(4), 339-345.

Henneberg, S. C. (2006). An Exploratory Analysis of CRM Implementation Models. Journal of Relationship Marketing, 4(3-4), 85-104.

Holcomb, T. R., \& Hitt, M. A. (2007). Toward a Model of Strategic Outsourcing. Journal of Operations Management, 25(2), 464-481.

Hutter, B., \& Jones, C. (2007). From government to governance: External influences on business risk management. Regulation \& Governance, 1(1), 27-45.

Jaakkolaa, E., \& Hakanen, T. (2013). Value co-creation in solution networks. Industrial Marketing Management, 42(1), 47-58.

Johnson, D. S., Clark, B. H., \& Barczak, G. (2012). Customer relationship management processes: How faithful are business-to-business firms to customer profitability? Industrial Marketing Management, 41(7), 10941105.

Karakostas, B., Kardaras, D., \& Papathanassiou, E. (2005). The state of CRM adoption by the financial services in the UK: an empirical investigation. Information \& Management, 42(6), 853-863. 
Keramati, A., Mehrabi, H., \& Mojir, N. (2010). A process-oriented perspective on customer relationship management and organizational performance: An empirical investigation. Industrial Marketing Management, 39(7), 11701185.

Kotler, P. (2012, 31 December 2012). Marketing Needs a Conscience. Marketing News, 46, 30.

Krasnikov, A., \& Jayachandran, S. (2008). The Relative Impact of Marketing, Research-and-Development, and Operations Capabilities on Firm Performance. Journal of Marketing, 72(4), 1-11.

Lai, K., Wong, C. W. Y., \& Cheng, T. C. E. (2010). Bundling digitized logistics activities and its performance implications. Industrial Marketing Management, 39, 273-286.

Levi, M., \& Gilmore, W. (2002). Terrorist finance, money laundering and the rise and rise of mutual evaluation: a new paradigm for crime control? . European Journal of Law Reform, 4(2), 87-114.

Lindgreen, A., Hingley, M. K., Grant, D. B., \& Morgan, R. E. (2012). Value in business and industrial marketing: Past, present, and future. Industrial Marketing Management, 41(1), 207-214.

Lindgreen, A., Palmer, R., Vanhamme, J., \& Wouters, J. (2006). A relationshipmanagement assessment tool: Questioning, identifying, and prioritizing critical aspects of customer relationships. Industrial Marketing Management, 35(1), 57-71.

Meadows, M., \& Dibb, S. (2012). Progress in customer relationship management adoption: a cross-sector study. Journal of Strategic Marketing, 20(4), 323344.

Meyers, M. K., Riccucci, N. M., \& Lurie, I. (2001). Achieving Goal Congruencein Complex Environments: The Case of Welfare Reform. Journal of Public Administration Research and Theory, 11(2), 165-202.

Morgan, N. A., Vorhies, D. W., \& Mason, C. H. (2009). Market orientation, marketing capabilities, and firm performance. Strategic Management Journal, 30(8), 909-920.

Morgan, R. M., \& Hunt, S. D. (1994). The Commitment-Trust Theory of Relationship Marketing. Journal of Marketing, 58(3), 20-38.

Nordin, F., Kindström, D., Kowalkowski, C., \& Rehme, J. (2011). The risks of providing services: Differential risk effects of the service-development strategies of customisation, bundling, and range. Journal of Service Management, 22(3), 390-408.

Norusis, M. J. (2002). SPSS guide to data analysis. Upper Saddle River, NJ: Prentice Hall.

Payne, A., \& Frow, P. (2005). A strategic framework for customer relationship management. Journal of Marketing, 69, 167-176.

Percival, G. L. (2009). Exploring the Influence of Local Policy Networks on the Implementation of Drug Policy Reform: The Case of California's Substance Abuse and Crime Prevention Act. Journal of Public Administration Research and Theory, 19(4), 795-815.

Porter, M. E., \& Kramer, M. R. (2011). Creating Shared Value. Harvard Business Review(Jan-Feb), 62-77. 
Resh, W. G., \& Pitts, D. W. (2013). No Solutions, Only Trade-Offs? Evidence about Goal Conflict in Street-Level Bureaucracies. Public Administration Review, 73(1), 132-142.

Richard, J. E., Thirkell, P. C., \& Huff, S. L. (2007). An Examination of Customer Relationship Management (CRM) Technology Adoption and its Impact on Business-to-Business Customer Relationships. Total Quality Management \& Business Excellence, 18(8), 927-945.

Robinson, J. P., Shaver, P. R., \& Wrightsman, L. S. (1991). Criteria for scale selection and evaluation. In J. P. Robinson, P. R. Shaver \& L. S. Wrightsman (Eds.), Measures of Personality and Social Psychological Attitudes. San Diego: Academic Press.

Ryals, L., \& Payne, A. (2001). Customer Relationship Management in Financial Services: Towards Information-Enabled Relationship Marketing. Journal of Strategic Marketing, 9, 3-27.

Sethi, R. (2000). New Product Quality and Product Development Teams. Journal of Marketing, 64(2), 1-14.

Sheth, J. N., Sisodia, R. S., \& Sharma, A. (2000). The Antecedents and Consequences of Customer-Centric Marketing. Journal of the Academy of Marketing Science, 28(1), 55-66.

Shum, P., Bove, L., \& Auh, S. (2008). Employees' affective commitment to change: The key to successful CRM implementation. European Journal of Marketing, 42(11-12), 1346-1371.

Stein, A. D., Smith, M. F., \& Lancioni, R. A. (2013). The development and diffusion of customer relationship management (CRM) intelligence in business-tobusiness environments. Industrial Marketing Management, 42(6), 855861. doi: http://dx.doi.org/10.1016/j.indmarman.2013.06.004

Theodosiou, M., Kehagias, J., \& Katsikea, E. (2012). Strategic Orientations, marketing capabilities and firm performance: An empirical investigation in the context of frontline managers in service organizations. Industrial Marketing Management, 41(7), 1058-1070.

Troy, L. C., Hirunyawipada, T., \& Paswan, A. K. (2008). Cross-functional integration and new product success: An empirical investigation of the findings. Journal of Marketing, 72(6), 132-146.

USDS. (2014). Country Reports on Terrorism 2013 (pp. 318). Washington DC: United States Department of State - Bureau of Counterterrorism.

Vandermerwe, S. (2004). Achieving Deep Customer Focus. MIT Sloan Management Review, 45(3), 26-34.

Zablah, A. R., Bellenger, D. N., \& Johnston, W. J. (2004). An evaluation of divergent perspectives on customer relationship management: Towards a common understanding of an emerging phenomenon. Industrial Marketing Management, 33, 475-489.

Zdanowicz, J. S. (2004). Detecting money laundering and terrorist financing via data mining. Communications of the ACM, 47(5), 53-55. 
Appendix A: Descriptive Statistics

Mean scores below 4 suggest that respondents tend to agree with the statement. Mean scores above 4 indicate the opposite

\begin{tabular}{|c|c|c|c|}
\hline Topic & Dimension & Mean & StdDev \\
\hline \multirow[t]{12}{*}{ 1. AML requirements } & Req1: The ways in which we capture data have changed as a result of AML & 2.76 & 1.85 \\
\hline & Req2: The ways in which we analyse our data have changed as a result of AML & 2.94 & 1.88 \\
\hline & Req3: Our approach to dealing with customers has changed as a result of AML & 3.12 & 1.69 \\
\hline & Req4: The frequency of our customer contact has changed as a result of AML & 4.09 & 1.67 \\
\hline & Req5: Staff training has changed as a result of AML & 2.10 & 1.39 \\
\hline & Req6: The data accessible to front-line staff has changed as a result of AML & 3.55 & 1.79 \\
\hline & Req7: AML has changed the job role of our front-line staff & 3.78 & 1.66 \\
\hline & Req8: AML has changed the job role for those handling customer data & 3.50 & 1.72 \\
\hline & Req9: AML projects are supported very strongly & 2.64 & 1.76 \\
\hline & Req10: AML permeates all parts of the organisation & 2.70 & 1.78 \\
\hline & Req11: Our organisation has designed systems with AML in mind & 3.08 & 1.64 \\
\hline & Req12: Front-line staff have clear responsibility for reporting on unusual data they observe & 2.07 & 1.67 \\
\hline \multirow[t]{4}{*}{ 2. CRM pre-requisites } & Pre1: There is no stated desire at all within the organisation for relationship management & 5.40 & 1.54 \\
\hline & Pre2: CRM does not have a strong champion at the top of the organization & 4.99 & 1.79 \\
\hline & Pre3: Senior management is not at all proactive in supporting CRM projects & 4.99 & 1.63 \\
\hline & Pre4: The organisational culture is not well suited to supporting CRM & 4.74 & 1.46 \\
\hline \multirow[t]{5}{*}{ 3. Technology } & T1: Emphasis is on using information to record transactions rather than as a strategic tool & 3.84 & 1.79 \\
\hline & T2: Front-line staff have access to only very basic customer data when handling customer enquiries & 4.46 & 1.74 \\
\hline & $\begin{array}{l}\text { T3: Computer system design and implementation are driven by internal accounting needs rather than external } \\
\text { customer needs }\end{array}$ & 3.68 & 1.60 \\
\hline & T4: Systems do not have access to attitudinal/buying behaviour data required to identify 'life events' & 3.15 & 1.74 \\
\hline & T5: Those handling customer direct marketing never co-ordinate their activities with front-line staff & 4.49 & 1.41 \\
\hline \multirow[t]{3}{*}{ 4. Customers } & $\begin{array}{l}\text { Cust1: Emphasis is on value to be achieved from customers today (perhaps through the sale of an additional } \\
\text { product) rather than on customers' life-time value }\end{array}$ & 4.24 & 1.93 \\
\hline & $\begin{array}{l}\text { Cust2: During customer contact the emphasis is always on conducting transactions rather than on updating } \\
\text { customer information systems }\end{array}$ & 3.53 & 1.41 \\
\hline & Cust3: The company is very poor at anticipating and reacting to customer needs (events-based marketing) & 4.05 & 1.76 \\
\hline \multirow[t]{3}{*}{ 5. Company } & $\begin{array}{l}\text { Co1: Emphasis is on transaction-driven marketing rather than customer-driven/life event-led marketing } \\
\text { Co2: The company always focuses on customer groups rather than the individual }\end{array}$ & $\begin{array}{l}4.36 \\
3.76\end{array}$ & $\begin{array}{l}1.57 \\
1.58\end{array}$ \\
\hline & $\begin{array}{l}\text { Co3: The company focuses on increasing sales volumes rather than relationship building as the route to } \\
\text { competitive advantage }\end{array}$ & 4.16 & 1.86 \\
\hline & Co4: CRM implementation does not permeate all parts of the organization & 3.55 & 1.81 \\
\hline \multirow[t]{2}{*}{ 6. Staff } & S1: Senior management never sets objectives which reflect the company stance on CRM & 4.24 & 1.61 \\
\hline & S2: Staff never use day-to-day contacts with customers as a market research opportunity & 3.60 & 1.62 \\
\hline
\end{tabular}




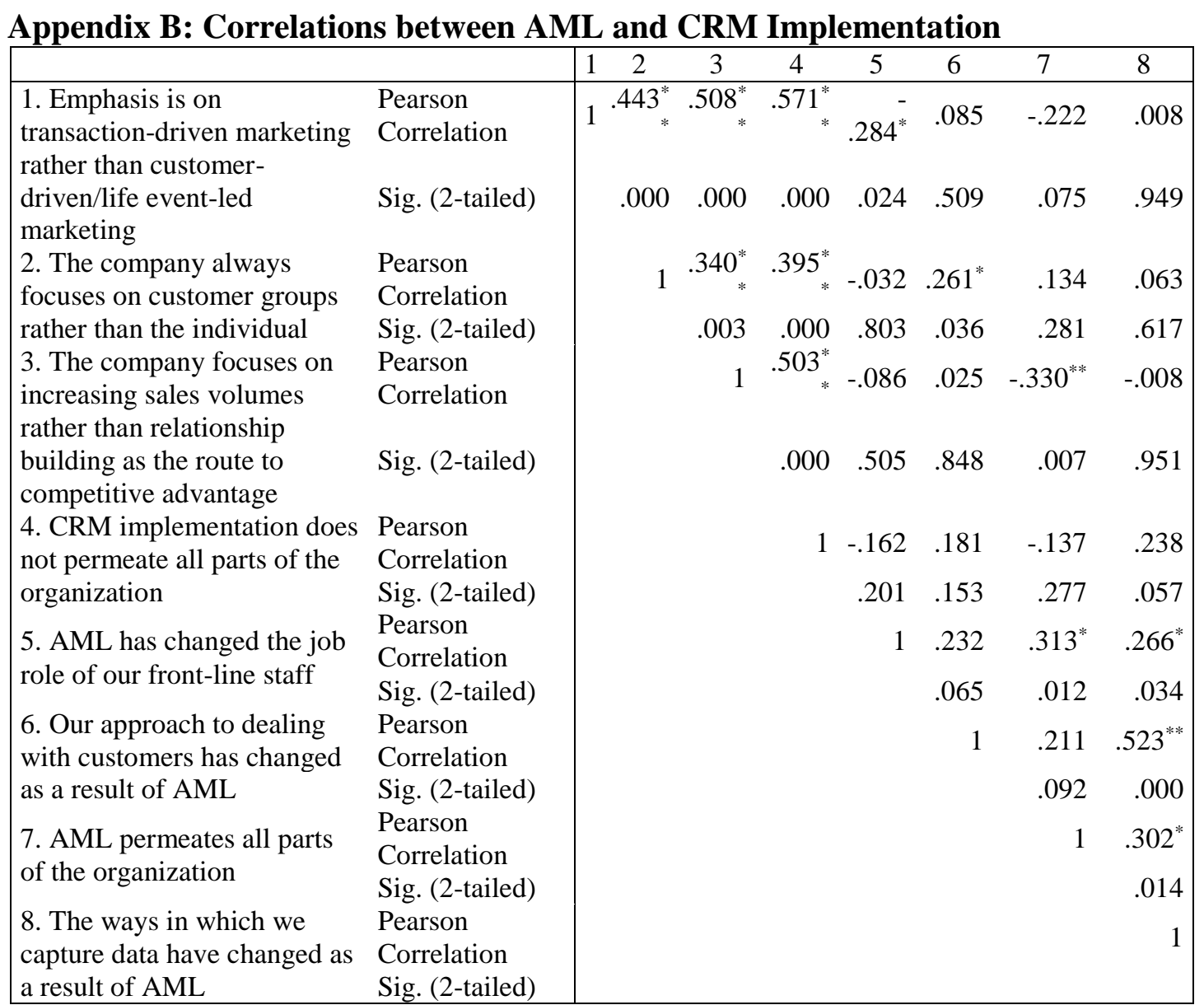

